\title{
ALCALDES PEDANEOS, MAYORDOMOS-JUECES Y ALCALDES DE BARRIO
}

352.075 .35

por

\author{
José Fariña Jamardo
}

SUMARIO: I. IMPORTANCIA.-II. NECESIDAD Y ORIGEN.-III. LOS "VILLICUS».-IV. JUECES Y MAYORDOMOS.-V. FUNCIONES DE LOS MAYORDOMOS-PEDANEOS.-VI. FORMAS DE DESIGNACION.-VII. ALCALDES PEDANEOS: EVOLUCION Y COMPETENCIAS.-VIII. LOS ALCALDES DE BARRIO.-IX. EL PASO DEL ANTIGUO REGIMEN AL LLAMADO CONSTITUCIONAL.- $X$. ALCALDES PEDANEOS Y DE BARRIO EN LOS PROYECTOS Y LEYES MUNICIPALES DE LOS SIGLOS XIX Y XX: 1. De 1823 a 1845. 2. DE 1845 a 1870. 3. De 1870 a 1924. 4. De 1924 a 1975.-XI. CONCLUSIONES.

\section{IMPORTANCIA}

En la práctica, y a veces en la legislación, se han confundido las denominaciones y funciones de los Alcaldes pedáneos, de los mavordomos-jueces y de los Alcaldes de barrio, y se les ha considerado como cargos residuales, inferiores y marginados. A pesar de ello, estas figuras de la Vida local han tenido y tienen aún una gran importancia dentro de la organización y el quehacer de nuestros Municipios, y su forma y expresión actual es consecuencia de un proceso de depuración y configuración a través del tiempo, con diversas alternativas en la evolución que han determinado desapariciones y resurgimientos, pues los Alcaldes pedáneos y de barrio 
en nuestra historia municipal, y al igual que el Ave Fénix, han sido capaces de volver a nacer de sus propias cenizas.

Tanto los pedáneos como los Alcaldes de barrio, o sus homónimos los mayordomos-jueces-pedáneos, hace tiempo desaparecidos, tienen una honda tradición en el Régimen local de nuestro país, y pueden seguir siendo instituciones valederas para el futuro. De aquí la necesidad de su estudio principalmente en relación con los Municipios formados por varios núcleos de población, en los que su existencia viene determinada por razones sociales y geográficas, 0 como una institución que constituye un medio de acercar la Administración local a los administrados, en las grandes urbes de nuestros días.

\section{NECESIDAD Y ORIGEN}

Inicialmente la necesidad de estos Alcaldes y mayordomos se produce por la existencia de entidades o poblados dentro de un término municipal o jurisdiccional separados de la capitalidad o núcleo principal, puesto que alguien ha de representar y actuar en nombre del Concejo o del señor en los núcleos alejados del centro o lugar en que se asienta el poder local. Pensemos que si el Municipio surge en la época romana, también nace en ella, como forma de asentamiento en el territorio, la «villae», sistema de explotación agraria que, partiendo del "palatium» del «domus» y de sus instalaciones urbanas, frumentarias y rústicas, produce nuevos asentamientos de siervos y colonos dentro de las tierras cuya explotación gobierna el «domus», pero alejadas ya de la villa urbana; instalaciones que suponen nuevos núcleos de población, disgregándose la unidad territorial primitiva de la "villae» en lugares, aldeas, casales y caseríos, sobre los cuales el "señor» ha de actuar por medio de delegados o representantes.

La «villae» conserva, no obstante, y en principio, su unidad y dependencia del "domus", primero romano y luego suevo o visigodo, hasta que con la Reconquista se fracciona y divide de hecho en varios núcleos, aunque el nombre de la «villae» siga consignándose en los documentos de la época como la unidad territorial de referencia. Con ella, en la diplomática medieval, aparecen los "vicus», que significan habitaciones agrupadas; los «vicani», o comunas rurales de propietarios; el caserío o "vigo", que más tarde se denominará también con el nombre de lugar o aldea. 
Realmente, y desde siempre, hay que distinguir entre el hábitat rural y el urbano; entre el hábitat disperso y el concentrado, y establecer las diferencias entre la citania y el castro, la civitas, el forum y la propia «villae». En la época de la dominación visigoda, según SAN IsIDORO DE SEvilla, existían los «vici», los «castella» y los «pagi», que eran las localidades que, teniendo una población numerosa, no alcanzaban la categoría de ciudad y giraban alrededor de un núcleo urbano, no sólo comercialmente, sino administrativa y municipalmente, al igual que lo hicieron los pueblos del alfoz en los Municipios de la época de la Reconquista y posteriores; los mismos que se convertirán siglos más tarde en "los pueblos agregados a un término municipal» de que hablan nuestras leyes de Régimen local del siglo $\mathrm{XIX}$.

\section{LOS «VILLICUS»}

En épocas en que no existen caminos, en que las comunicaciones son difíciles, los que detentan el poder o el señorío sobre un territorio determinado: comisso, terra, jurisdicción, coto, villa, necesitan estar representados en las entidades de población separadas y alejadas de la civitas o la villa urbana, y lo hacen, ya en los tiempos de la dominación romana y de la visigoda, por medio de los «villicus». El villicus era un delegado del «domus» o del señor jurisdiccional, que le nombraba, y al cual representaba en la feligresía, pagi o aldea correspondiente. Era también el villicus el funcionario encargado de mantener el orden en los pueblos, y era igualmente, en las épocas citadas, el administrador de la «villae», el que dirigía los trabajos en la misma, el delegado y representante del señor.

Con la Reconquista y la presura de las villas, estos villicus acumularon a sus funciones anteriores la cobranza de las penas pecuniarias impuestas por delitos y crímenes. $Y$ en la nueva situación creada, en vez de dirigir a los siervos en los trabajos agrícolas como anteriormente, arrendaban a los sucesores de éstos las glebas que aquéllos cultivaban por cuenta del «dominus». Actuaban de hecho como agentes fiscales del señor o del rey, y su oficio, aunque lucrativo, era odioso y odiado. Procedían de la clase popular y se encontraban divididos, a veces, en mayordomos grandes y pequeños. Los "reguengueiros», para estär en regla, no podían hacer la 
recolección de los frutos sin llamarlos, y por eso los nominaban también como «mayordomos de las eras».

\section{JUECES Y MAYORDOMOS}

En la Edad Media, el villicus romano, convertido ahora en mayordomo, puede representar a la Corona en juicio. Pero, paralelamente a la presencia del mayordomo-administrador, se señala la presencia del «judex» o «joiz», elegido directamente por la propia comunidad vecinal, que es una figura de origen oscuro, aunque su existencia puede demostrarse documentalmente, y así lo encontramos en una «inquirición» del año 915, en la que se dice: «Item, estes devanditos omees erguen dantre si Joiz, et outorga o Sancto Jacobo de Gallecia, et pois vam al Rey que o confirme." Lo que nos pone de manifiesto que ya antes del 915 existía el joiz, como juez de una feligresía o una aldea, y que los tales joiz eran elegidos por votación popular. Según Alberto Sampaio, estos jueces en un principio fueron todos elegidos por votación directa de los vecinos de la entidad de población en que administraban justicia. $Y$ cita a "Pelagio Mónaco, clérigo, que fue juez entre erdadores rendeiros», insistiendo en que los primitivos jueces de las feligresías fueron creados por 'el pueblo. Más tarde, cuando empezó a establecerse una administración regular, tenía que confirmarlos el rey o el señor; y en una tercera etapa pasaron a ser designados por el señor o por el rey. Entonces actuaban ya, los designados por el monarca, como representantes suyos e inspectores de las propiedades de la Corona.

Teniendo en cuenta el pequeño ámbito territorial en que desarrollaba su cometido una sola persona, muchas veces ejercía las funciones administrativas y judiciales, lo que originó la existencia del mayordomo-juez-pedáneo, que en la denominación más corriente y abreviada pasó a ser el mayordomo-pedáneo, tan característico en las feligresías y aldeas rurales del noroeste peninsular. Sin embargo, la dualidad de mayordomo y juez siguió existiendo en muchas entidades y durante muchos años, al igual que existia la Justicia y Regimiento en las municipalidades. En los cotos que formaban un término jurisdiccional cerrado, dependientes de una iglesia o monasterio, y corrientemente constituidos por una sola feligresía, y cuyos moradores eran considerados como vasallos, libres o inge- 
nuos, de la íglesia o monasterio, el superior de la comunidad eclesial los regía y administraba por medio de un juez y un mayordomo, aunque a veces una sola persona reunía las atribuciones de mayordomo y juez.

Cuando la parroquia o aldea integraba con otras una jurisdicción, el señor de la misma, que la regía y administraba con autoridad propia, nombraba jueces, escribanos o mayordomos. En este caso el juez se designaba corrientemente y con el carácter de único para toda la jurisdicción, residiendo en la cabecera de la misma. En las aldeas o parroquias separadas existían mayordomos-pedáneos que cuando eran designados por los vecinos de la feligresía o aldea tenían que convalidar su nombramiento ante el juez de la jurisdicción o ante el propio señor civil o eclesiástico, siendo éste, en la mayoría de los casos, quien los designaba directamente.

En la jurisdicción del Valle de Lorenzana (Lugo), y por privilegio otorgado por SANCHO IV, confirmado después por todos los reyes de Castilla hasta FELIPE IV inclusive, para la cabecera de la jurisdicción se nombraba cada año Alcalde mayor y Justicia ordinaria, que la administraban «in solidum", pero, al mismo tiempo, cada una de las parroquias que componían el Valle de Lorenzana nombraba también cada año, y por mayoría de votos, juez ordinario, al que se asignaban las mismas competencias civiles y criminales que a los demás jueces de la misma denominación. La distinción entre mayordomo y mayordomo-pedáneo, en esta época, puede establecerse, por tanto, y en términos generales, en que los primeros realizaban sólo funciones administrativas, y los segundos añadían a las administrativas las judiciales, ejercidas éstas por delegación del juez de la jurisdicción y limitadas en la cuantía.

En cuanto al nombramiento de mayordomo por parte de los señores en el siglo XIII, se dice en la postura $\mathrm{X}$ del Código dado por Alfonso X el SABIo a la Tierra de Santiago, en el año 1252, lo siguiente: «Et mayordomo de merino mayor non aya otro mayordomo so sí. Ricome que la terra tenga, ponga su mayordomo; mas el mayordomo de su prestamero non aya otro mayordomo so sí. El Ricome tal prestamero dé en la terra, que pueda sanar el danno que ficiere bien et complidamientre; si non el Ricome sea tenudo de sanar todo lo danno por el prestamero entregamientre. Et si dos prestameros tovieren la terra de consuno, o partan la terra por medio, o pongan entramos un mayordomo et non más". 
ALfonso $\mathrm{X}$ establece así una jerarquía, buscando la unidad de mando dentro de cada "terra", y determinando garantías para los habitantes de la misma. Sin embargo, y en lo que a la Tierra de Santiago se refiere, estas disposiciones ya habían sido tomadas siglo y medio antes por Gelmírez, el cual, en el XIV de sus Decretos sobre administración, que trata de los vicarios, dispone: «Los caballeros y todos aquellos que gozan de principado pongan en sus administraciones tales vicarios - vigairos o mayordomos- que, si por ventura obraren algo contra la Justicia de los Decretos, tengan con qué responder de las caloñas emergentes. De lo contrario, satisfagan sus Señores los daños causados y las caloñas por injusticia».

\section{FUNCIONES DE LOS MAYORDOMOS-PEDANEOS}

Los mayordomos-pedáneos nombrados por los reyes y los señores eran los encargados de percibir los derechos, tributos, diezmos o rentas que a los mismos correspondían. Cobraban igualmente "las multas o caloñas en que incurrían los reos aparte de los procedimientos judiciales». Pero, al igual que al lado del Merino mayor, como órgano superior de la administración de justicia, existían los majorinos, al lado de los mayordomos mayores o principales había mayordomos menores de feligresía o poblado. Ciertamente, el término mayordomo se empleó también en otros aspectos, como en el orden eclesiástico, para designar al administrador de la fábrica de la iglesia, y al que conocían con los nombres de mayordomo-fabriquero, mayordomo-lucernario, mayordomo-luminario y mayordomo-primiciero.

Los mayordomos-pedáneos, además del cobro de multas y otras acciones de tipo fiscal, como su intervención directa en los encabezamientos y repartos de cupos, en los aprovechamientos vecinales y en la policía y conservación de caminos, tenían distintos y variados cometidos, tanto en el orden militar: alarmas, fachos, centinelas, reclutamiento de soldados, como en el orden judicial, en cuanto delegados del juez jurisdiccional y ejecutores de sus mandatos y órdenes, además de ejercer funciones propias de la justicia dentro de ciertos límites, como las reclamaciones a los deudores hasta cien maravedíes, el depósito y multa del ganado mayor o menor aprehendido en los terrenos de la feligresía y otras sucinta 
o detalladamente expuestas, según los casos, en los interrogatorios del "Catastro de Ensenada» a mediados del siglo xvirI.

La intervención del mayordomo-pedáneo es constante en la formación de censos, estadísticas y demás servicios que demanda el rey. Representa a la entidad en el Concejo y ante los tribunales y promueve los intereses y servicios de la comunidad. Ha de cumplimentar las "veredas» y servicios judiciales y gubernativos y dirigir la que ahora llamamos policía rural, en especial en lo que atañe a la conservación de caminos.

Es responsable no sólo en lo referente a los aprovechamientos de los bienes de la entidad, sino de la plantación y conservación de los montes y plantíos reales. Esta obligación está ampliamente determinada en el Auto General de 1 de noviembre de 1792, a tenor del cual a los mayordomos-pedáneos de cada feligresía correspondía mantener siempre cerrados los reales viveros; impedir la ocupación de terreno de las dehesas por los propietarios colindantes; concurrir a los plantíos; vigilar las cortas de árboles; hacer que los montes de comunidades y particulares se críen y conserven como los comunes, y otras. Tenían que cuidar, además, de que se cumpliera puntualmente lo ordenado en los Autos de su feligresía, y para ello estos Autos se le entregaban bajo recibo "como responsables del arbolado» que eran. Es significativa a este respecto la decimotercera de las disposiciones que el Auto contiene: «Que así como las Justicias han de pasar a sus sucesores todos los documentos del ramo de arbolados, así también los mayordomos, rexidores, tenientes y procuradores entregarán a los suyos el testimonio que se les dará del actual arreglo y más órdenes que les comuniquen, entregando al mismo tiempo las Reales Dehesas con expresión de su estado, para evitar en lo adelante dudas y disculpas, y del que cada uno sacará el competente resguardo, mediante los citados mayordomos son los principales responsables de los Reales Plantíos».

Conviene distinguir, sin embargo, a estos mayordomos de los llamados mayordomos de propios, que eran simples oficiales elegidos anualmente por los pueblos, y a cuyo cargo corría la administración de los propios y caudales del ramo, debiendo llevar cuenta exacta y puntual de todas las partidas de entrada y salida, con cargo y data de su distribución y pagos. 


\section{FORMAS DE DESIGNACION}

Las formas de elección y nombramiento de los mayordomospedáneos no se limitaban, como señala MiÑano en su Diccionario, al nombramiento por los vecinos o designación por los jueces, sino que fueron a través de los tiempos las siguientes: directa del señor civil o eclesiástico; directa del juez ordinario de la jurisdicción; elección por los vecinos; elección por los vecinos confirmada con la expedición de título por el juez; propuesta por los vecinos de tres o más candidatos para que de entre ellos designe mayordomopedáneo el señor jurisdiccional, y otras más como variantes particulares sobre las indicadas, que podemos considerar como generales y fundamentales.

En cuanto a formas originales y curiosas de designación de pedáneos, una ya desaparecida y otra vigente, quiero dejar constancia por su singularidad de dos de ellas privativas de mi tierra gallega. La primera que rigió en la parroquia de Taboadelo, en la cual el cargo de pedáneo se adjudicaba entre todos los vecinos de la parroquia, mediante el sistema de pujas a la llana, al mejor postor, o sea, al vecino que más dinero ofrecía por ostentar y desempeñar el cargo, destinando el dinero de la subasta a abonar el importe de la comida para todos los parroquianos con la que se festejaba la toma de posesión del nuevo mayordomo-pedáneo para un año.

La segunda, que aún subsiste en la parroquia de San Fiz de Quión y otras del Ayuntamiento de Touro (La Coruña), parroquia en donde la designación del pedáneo tiene lugar el día 1 de enero de cada año a la salida de la misa parroquial entre los vecinos cabezas de familia, incluidos los que contrajeron matrimonio el año anterior y que no hayan ejercido como pedáneos, figurando así como elegibles en la lista correspondiente y por orden de antigüedad en el estado de "casado». El pedáneo que termina su mandato, ayudado por un vecino que tiene la lista completa de los candidatos obligados al cargo y ante todos los feligreses que quieran presenciar el acto, procede a verificar el sorteo, utilizando para ello una baraja corriente de cuarenta cartas. Después de barajar y dar a cortar - para que no haya trampa-, el pedáneo que va a cesar comienza a dar vuelta a las cartas, al tiempo que el vecino que tie- 
ne la lista lee los nombres de los en ella incluidos. Al que le toca el rey de espadas queda designado pedáneo para el año que se inicia. Si cantados todos los nombres de la lista no aparece el rey de espadas, el lector vuelve a repetir los nombres y el nombrado cuando salga el rey de espadas es designado y acatado por todos como pedáneo hasta el año siguiente, en que se vuelve a repetir la operación.

\section{ALCALDES PEDANEOS: EVOLUCION Y COMPETENCIAS}

El Alcalde pedáneo, o más bien Pedáneo - ya que el nombre de Alcalde es de origen árabe y posterior-, nace en la época de la dominación romana, con funciones de juez-pedáneo, puesto que entendía en las causas leves, juzgando por sí mismo, sin tribunal, en el acto y de pie, lo que da origen a su denominación, ya que etimológicamente "pedáneo» es lo que tiene un pie de dimensión, y supone la autoridad ejercida en un ámbito territorial mínimo - que más tarde incluso, y en ciertas regiones, se llamará pedanía-, es decir, una parroquia, una aldea o un caserío. De estos hechos y circunstancias nació el dicho popular "mandas menos que un Pedáneo» y las alusiones, los dichos y chanzas populares o literarias referidas a tan pequeño y reducido mando.

Mayordomo-pedáneo, como hemos visto, es la denominación que en algunas regiones y comarcas españolas se da también al que en muchas otras se conoce y llama Alcalde pedáneo, cargo éste regulado en la Nueva Recopilación, Libro III, Título IX, Ley 25, con el nombre de Alcalde pedáneo u ordinario de las aldeas. Y así se les llama en la Nueva Recopilación porque los Alcaldes pedáneos gobernaron siempre parroquias, aldeas y entidades o poblaciones de pocos habitantes, ejerciendo corrientemente una doble función: judicial y administrativa, aunque en ciertos casos con predominio de la judicial. En la Nueva Recopilación se les atribuyen facultades propias de orden civil y criminal, originadas en la costumbre y en las decisiones del Consejo de Castilla, en lo que se refiere a pueblos y lugares determinados. Esta jurisdicción pedánea, cuyo ejercicio se fundamentaba en la falta de Alcaldes o jueces legítimos en el territorio a que se extendía, llegó a facultar más tarde a su titular para entender en todo lo concerniente a la policía y actos de gobierno de su territorio. 
Según Celestino de FuEsCA, los Alcaldes pedáneos u ordinarios de las aldeas «son los jueces de los pueblos que dependen de los Corregidores, Alcaldes mayores u ordinarios de las cabezas de partido a quienes están subordinados».

En un principio sólo conocían en las causas civiles hasta la cantidad de 600 maravedíes, pero con posterioridad dicha cuantía fue elevada en la rama de lo civil, cuyos pleitos dirimían mediante juicio verbal; y en las causas criminales, según establecía la Ley 20, Título IV, Libro III, de la Nueva Recopilación, podían prender a los reos, pero no sustanciar sus procesos, ni soltarlos; y podían igualmente castigar las faltas de respeto, desobediencia $u$ otros cualesquiera excesos que no fuesen de gravedad, con prisión de hasta tres días, y ello sin necesidad de dar parte al Corregidor o Alcalde mayor.

Estos Alcaldes de las aldeas, en uso de la jurisdicción pedánea que la Ley les asignaba y que fue ampliada por la R. P. de 2 de septiembre de 1778, eran competentes para conocer y resolver en las demandas, pleitos y juicios que ocurrieren en sus respectivos distritos hasta la cantidad de treinta reales, oyendo ante sí a las partes, sin admitir pedimentos, ni formar procesos, ni guardar orden ni solemnidad en juicio, procediendo a la condena o absolución de plano y ejecutando sus sentencias, sin que contra ellas se pudiese interponer ni admitir apelación.

Conocían también los Alcaldes pedáneos de las infracciones cometidas contra las Ordenanzas de sus respectivos pueblos y aldeas $\mathrm{y}$, en especial, en lo concerniente a la conservación de campos y sembrados, a la regulación de las faenas agrícolas y levantamiento de cosechas. Estaban también facultados para formar inventario de los bienes de sus vecinos difuntos y para intervenir en las particiones de los mismos.

Estos Alcaldes pedáneos se conocían también con el nombre de «Regidores», y las regulaciones legales de la época se refieren indistintamente a los «Regidores y Alcaldes pedáneos». Sin embargo, conviene distinguirlos de los llamados Alcaldes de la Hermandad, que originariamente tenían el destino de perseguir a los salteadores y ladrones, pero que posteriormente, en algunas localidades, se convirtieron en unos jueces nombrados cada año por los pueblos para conocer de los delitos y excesos cometidos en el campo. Eran jueces legos y usaban vara. En otro orden de cosas, las Hermandades tu- 
vieron una gran importancia como movimiento local comunitario, especialmente en Galicia, y los Reyes Católicos potenciaron con fines políticos y de gobierno la que se denominó Santa Hermandad.

\section{LOS ALCALDES DE BARRIO}

Los Alcaldes de barrio, a diferencia de los pedáneos, cuya antigüedad es notoria, tienen un origen más reciente. El concepto etimológico de Alcalde de barrio se corresponde con el ámbito territorial de su actuación. Barrio se deriva de la palabra árabe «barr», que significa tierra, campo, afueras. De aquí que los barrios primitivos fuesen sinónimos de los arrabales o extremos de una población, como señala Blanco MaRTínez.

Los Alcaldes de barrio en nuestro país aparecen en el reinado de CARLOS III, quien reglamenta sus atribuciones en las Leyes 10, Título XXII, Libro III, y 1. ${ }^{a}$, Título XIII, Libro V, de la Novísima Recopilación. CARLos III, por la Instrucción de 21 de octubre de 1768, dividió la Corte en ocho cuarteles y otros tantos barrios, extendiéndose luego esta división en barrios a las ciudades más importantes de España por la Real Cédula de 13 de agosto de 1769, que establece la división en cuarteles y barrios de las ciudades en que están asentadas las reales chancillerías y audiencias, creando los Alcaldes de cuartel y de barrio de las mismas.

Conforme a lo dispuesto en las reglamentaciones citadas recogidas en la Novísima Recopilación, los Alcaldes de barrio en Madrid y en otras ciudades eran unas personas que se elegían anualmente por los vecinos de su demarcación, o que se designaban por las autoridades superiores, para cuidar de la quietud y policía del barrio, para lo cual tenían asignada jurisdicción pedánea, con subordinación a los respectivos Alcaldes de cuartel. Los Alcaldes de barrio, como delegados de la autoridad municipal, tenían a su cargo funciones referentes a la policía de seguridad y de limpieza, matrícula de vecinos, asiento de posaderos, fuentes y otras; funciones que, como veremos, van a ser muy mermadas con la nueva legislación que se produce después de la Constitución de Cádiz de 1812. 


\section{EL PASO DEL ANTIGUO REGIMEN AL LLAMADO CONSTITUCIONAL}

¿Qué tratamiento da a las figuras del Alcalde pedáneo y del Alcalde de barrio la legislación que regula los llamados Ayuntamientos constitucionales? ¿Es respetuosa esta legislación con los "puebios agregados» y sus peculiaridades y necesidades? Empecemos por decir que el tópico repetido hasta la saciedad de que el Régimen local español a partir de las Cortes de Cádiz fue una copia exacta del francés, no es cierto en lo que al reconocimiento de las entidades naturales o menores se refiere, pues mientras en Francia pasaron a ser Municipios todas las parroquias rurales y aún hoy lo siguien siendo, en España el mapa municipal, en algunas regiones, no reconoció a dichas entidades y por ello fue tan artificial como el provincial. $\mathrm{Y}$ en cuanto a los Alcaldes pedáneos y de barrio, el tránsito del antiguo al nuevo régimen se verificó entre avances y retrocesos, acuerdos y trasacuerdos, normas y contranormas, conforme al carácter absolutista o liberal de los que gobernaban el país.

La Constitución de Cádiz de 1812 rompe, en cuanto al Régimen local, con los antiguos moldes y establece una legislación uniforme para todo el territorio del Estado con su tantas veces citado artículo 310: "Se pondrá Ayuntamiento en los pueblos que no lo tengan y en que convenga le haya, no pudiendo dejar de haberlo en los que por sí o con su comarca lleguen a mil almas, y también se les señalará término correspondiente», sobre el que se asentará el nuevo Régimen local, pero el texto de los doceañistas no se ocupa ni habla de los Alcaldes pedáneos y de barrio, ya que un texto constitucional no puede descender a estos pequeños detalles.

Pero tampoco el examen de estas figuras y la de los mismos pueblos agregados, como sujetos de un régimen especial, se realiza en las discusiones que sirvieron de base al establecimiento de la Constitución, como las que tuvieron lugar en la Comisión de Constitución en sesión de 15 de febrero de 1812 o en la del 27 del mismo mes, en la que se presentó un Proyecto de Decreto sobre Ayuntamientos, $y$ en el que se señalan las condiciones para que «cualquier pueblo que por sus particulares circunstancias de agricultura, industria o población" llegue a tener Ayuntamiento, para señalar seguidamente «que los pueblos que no se hallen con estas circunstancias seguirán agregados a los Ayuntamientos a que lo han estado 
hasta aqui, mientras que la mejora de su estado político no exija otra providencia, agregándose al más inmediato los que se formaren nuevamente", lo que implica de hecho la subsistencia de pueblos sin Ayuntamiento y agregados a un término municipal, para los que no se establece ninguna regulación especial. Determina, no obstante, que a fines electorales, "particularmente en aquellos pueblos en que una numerosa población o la división y distancia de los pueblos o parroquias que han de agregarse para establecer su Ayuntamiento podría hacerse embarazoso, se formarán Juntas de parroquia».

En el Decreto de las Cortes de Cádiz de 23 de mayo de 1812, sobre formación de los Ayuntamientos constitucionales, se reiteran los preceptos anteriormente indicados, señalando la posibilidad de que los pueblos que no lleguen a mil almas puedan tener Ayuntamiento propio, y disponiendo que los pueblos que no se hallen en estas circunstancias seguirán agregados a los Ayuntamientos «a que lo han estado hasta aquí", agregándose al más inmediato en su Provincia los que se formaren nuevamente y los despoblados con jurisdicción. Continúan las Juntas de parroquia a fines electorales, y estas disposiciones se conservan y repiten en la Instrucción para el gobierno económico-político de las Provincias de 23 de junio de 1813.

Por otro lado, la separación de poderes establecida lleva aparejada la desaparición en la normativa legal de las figuras del juezpedáneo, mayordomo-pedáneo, o mayordomo-juez-pedáneo, cuyas denominaciones, en realidad, eran sólo privativas de algunas regiones, y cuyas funciones resultaban equivalentes a las de los Alcaldes pedáneos $\mathrm{u}$ ordinarios de las aldeas regulados en la Nueva Recopilación. Sin embargo, los Alcaldes pedáneos siguen simultaneando el ejercicio tradicional de funciones judiciales y administrativas, hasta que se publica el Decreto de 22 de octubre de 1858.

\section{ALCALDES PEDANEOS Y DE BARRIO EN LOS PROYECTOS Y LEYES MUNICIPALES DE LOS SIGLOS XIX Y XX}

1. DE 1823 A 1845

Pero en las anteriores disposiciones no se habla de quién va a gobernar o dirigir por derecho propio o por delegación estos pueblos agregados. Es la Ley para el gobierno económico-político de las 
Provincias de 3 de febrero de 1823, la primera que dispone algo al respecto en el artículo 187: "Cuando muchos barrios, aldeas, lugares o caseríos separados a alguna distancia formen una sola población para tener Ayuntamiento, cuidará de cada uno de ellos para tomar providencias urgentes y para dar cuenta a los Alcaldes de cualquier ocurrencia que lo exija, uno de los capitulares que viva en los mismos barrios, aldeas, lugares o caserios; y donde no lo hubiere se nombrará por el Ayuntamiento un Celador en la forma prevenida». Con lo que aparece una nueva denominación: la de Celador, que se usaba y usa en algunas regiones para designar a los que cooperan con los Alcaldes pedáneos o de barrio, pero que en esta Ley de 3 de febrero de 1823 se les hace equivalentes a los mismos.

En los dictámenes emitidos por la Comisión de Cortes en 26 de marzo de 1838 y 12 de junio del mismo año al Proyecto de ley sobre organización de los Ayuntamientos, formulado por el Ministro de la Gobernación, MARQués DE Someruelas, en 3 de febrero de 1838, se dice: "Cuando. un Ayuntamiento se componga de varias parroquias, feligresías o poblaciones rurales, habrá un Alcalde pedáneo en cada una de ellas, elegido por el Alcalde de todo el distrito municipal, de entre tres candidatos de la clase de elegibles, nombrados por los vecinos electores de aquella misma parroquia, feligresía o población. Cuando en ella residiere un individuo del Ayuntamiento será éste el Alcalde pedáneo, y si residieren dos o más, lo será el que hubiere obtenido mayor número de votos. El Gobierno podrá, a instancia de un Ayuntamiento, crear también un Alcalde pedáneo en cualquier arrabal, barriada, pago u otro establecimiento rústico o urbano separado del centro de la población, cuando la necesidad o utilidad pública lo exija». Su nombramiento se verificará como en este artículo - que es el $5 .^{\circ}$ - se expresa. A su vez, en el artículo 51 se dispone que cuando en las sesiones del Ayuntamiento se trate de negocios que interesen a alguna o algunas parroquias o feligresías, se convocará y asistirán indispensablemente el Alcalde o Alcaldes pedáneos respectivos, con voz para la debida instrucción, pero sin voto. En el dictamen de 12 de junio de 1838, el Título VII se llama "De los Alcaldes pedáneos» y comprende los artículos 19 a 23, en los que se regulan las facultades y atribuciones de los Alcaldes pedáneos para ejercerlas en las respectivas parroquias, aldeas o pagos, señalando también que el Alcalde pedáneo representará en juicio y fuera de él al vecindario de su parroquia o término cuando se trate de acciones y derechos que a ellos solos 
competen, previo el asentimiento de los vecinos y el conocimiento que dará al Ayuntamiento.

Como vemos, la regulación sobre Alcaldes pedáneos a partir de 1838 comienza a ser intensa y detallada, enlazando con la de la Nueva Recopilación sobre el Alcalde ordinario de las aldeas, pero siguen sin aparecer en las leyes municipales los Alcaldes de barrio regulados por CARLOS III. Las disposiciones sobre Alcaldes pedáneos de que hemos hecho mención permanecen en el Proyecto de ley sobre organización de los Ayuntamientos, de Martín Carramolino, de 12 de septiembre de 1839, y en el de Calderón Collantes, de 21 de marzo de 1840, que, dictaminado en 21 de marzo de 1840, se convirtió en la Ley de organización y atribuciones de los Ayuntamientos de 14 de julio de 1840, aprobada por las Cortes y publicada en 21 de julio de 1840, sin que llegase a ser aplicada, y que en su artículo 4. disponía: "Cuando un Ayuntamiento se componga de varias parroquias, feligresías o poblaciones rurales, habrá en cada una de ellas un Alcalde pedáneo nombrado por los vecinos electores de aquella misma parroquia, feligresía o población». Esta Ley dedica a los Alcaldes pedáneos y sus atribuciones todo el Título XII, artículos 79 al 83. En parecidos términos se ocupa de los Alcaldes pedáneos la Ley de organización y atribuciones de los Ayuntamientos de 8 de enero de 1845, que en el Título II dice: "Cuando el distrito de un Ayuntamiento se componga de varias parroquias, feligresías o poblaciones apartadas entre sí, se nombrará un Alcalde pedáneo para cada una de ellas, excepto el caso de que en la misma resida alguno de los Tenientes».

\section{DE 1845 A 1870}

Los Alcaldes de barrio aparecen en el Proyecto de leyes orgánicas para el gobierno y administración provincial y municipal de Patricio DE LA Escosura, de 7 de mayo de 1856, cuyo artículo 56 pone de relieve la existencia de varios Alcaldes dentro de un término municipal, que ya se infiere y deduce de la legislación anterior, al señalar que donde hubiere dos Alcaldes se dividirá el término en dos cuarteles iguales, y si hubiere tres o más Alcaldes, en tantos cuarteles como Alcaldes haya menos uno. Los Alcaldes de cuartel representan al Gobierno en el cuartel, al igual que el Alcalde primero lo hace en el término, pero bajo su dependencia. El artícu- 
lo 278 dispone que los Alcaldes de barrio ejercerán las funciones que les delegaren los Alcaldes de cuartel, conformándose con las disposiciones del Alcalde primero y del Gobernador. Los Alcaldes constitucionales que ejerzan funciones judiciales lo hacen bajo la dependencia del juez o tribunal judicial y, juntamente con los Alcaldes de barrio, quedan sujetos a responsabilidad judicial. En cambio, gubernativamente, dependen: los Alcaldes primeros, de los Gobernadores; los de cuartel, del Alcalde primero y del Gobernador, y los Alcaldes de barrio, del de cuartel, Alcalde primero y Gobernador.

El Proyecto fue aprobado definitivamente en 24 de junio de 1856, y en él se señala que todo arrabal o parte separada o apartada del casco ha de formar un barrio sea cualquiera su población, y que en cada barrio habrá un Alcalde de barrio que será nombrado por el Alcalde constitucional, Presidente del Ayuntamiento, a propuesta en terna de éste, siendo el cargo de Alcalde de barrio gratuito, honorífico, obligatorio y revocable por el Alcalde primero con acuerdo del Ayuntamiento. No se hace mención ni referencia alguna a los Alcaldes pedáneos.

Pero los Alcaldes pedáneos resurgen con fuerza, otra vez, en el Proyecto de ley de Ayuntamientos de Posada Herrera, de 25 de octubre de 1860, en cuyo artículo 10 se dice que: "cuando el término de un Ayuntamiento se componga de varias parroquias, feligresías o poblaciones apartadas entre sí, habrá un Alcalde pedáneo en cada una de ellas, a menos que en las mismas resida alguno de los Tenientes», determinando en el artículo 134 que los Alcaldes pedáneos serán nombrados y separados por el Gobernador civil de la Provincia, lo que supone un retroceso notable con referencia a la legislación anterior y una intromisión gubernativa en la vida municipal, que pugna con el mínimo de autonomía necesaria. Por eso no es de extrañar que en contra del dictamen mayoritario de la Comisión se formulase otro minoritario por los señores Alonso MARTfNez y PÉREZ ZAMORA, proponiendo la existencia de un Alcalde pedáneo en cada barrio, "que, como delegado del Alcalde y bajo la dependencia y dirección de éste, ejercerá la parte de funciones administrativas que le delegue, y que será nombrado por el Alcalde-Presidente del Ayuntamiento, a propuesta en terna de éste, y cuya revocación podía hacer el Alcalde, con acuerdo del Ayuntamiento". Se prevenía que el Alcalde pedáneo asistiría a las sesiones del Ayuntamiento cuando en ellas se tratasen asuntos de su demarcación. 
Mas en el Proyecto que cinco años después formula el mismo Posada Herrera, bajo el título de Ley sobre organización y atribuciones de los Ayuntamientos, que lleva fecha 12 de marzo de 1865, al igual que en el dictamen de la Comisión, ya no se habla de Alcaldes pedáneos, y se regulan los Alcaldes de barrio y de cuartel, lo mismo que en el Proyecto de Escosura, como delegados de los Alcaldes constitucionales, y de una forma extensa. Hay que tener presente que en el orden municipal durante todo el siglo XIX, pero especialmente en sus tres primeras partes, las derogaciones, restauraciones, puestas en vigor de leyes que sólo duran días, proyectos que se aprueban y no se promulgan, constituyen una constante que a cualquiera le produce un fuerte mareo legislativo. Así, la Ley para el gobierno económico-político de las Provincias de 3 de febrero de 1823, o de 2 de marzo de 1823, como señala Adolfo Posada, fue derogada a los pocos días de entrar en vigor por Fernando VII, una vez que los Cien Mil Hijos de San Luis lo restablecieron en el trono como monarca absoluto, pero volvió a ser instaurada el 15 de ocubre de 1836, estando en vigor hasta el 8 de enero de 1845, y luego nuevamente en 1854 hasta el Decreto derogatorio de 16 de octubre de 1856, que restableció a su vez la de 8 de enero de 1845. Asimismo, la Ley de Ayuntamientos de 1840 se mandó poner en ejecución por el Real Decreto de 30 de diciembre de 1843, y el Reglamento para su ejecución se publicó el 6 de enero de 1844, pero la Ley de 8 de enero de 1845 lo dejó sin efecto. En cuanto a la Ley municipal de 5 de julio de 1856, fue declarada sin valor por un Real Decreto del 16 de octubre del mismo año, que restableció la legislación anterior. En cambio, la nueva Ley para el gobièrno y administración de las Provincias puesta en vigor el 25 de septiembre de 1863, si bien reformada en distintos puntos, persistió hasta el Decreto-Ley de 21 de octubre de 1868, que, aunque con ciertas reformas, vuelve a la Ley de Ayuntamientos de 8 de enero de 1845.

En la Ley municipal de 20 de agosto de 1870 se dice que en cada barrio habrá un Alcalde del mismo que, bajo la dependencia del Teniente respectivo, ejercerá la parte de funciones administrativas que éste le delegue, siendo Alcalde de barrio en los pueblos que tengan Junta Vecinal el Presidente de la misma. Y que en los pueblos que formando con otro término municipal tengan territorio propio, aguas, pastos, montes o cualesquiera derechos que les sean peculiares, conservarán sobre ellos su administración particular, 
que se ejercerá por medio de una Junta compuesta de dos o cuatro vocales y un Presidente, elegidos directamente por los vecinos y de entre ellos mismos. Aquí el Alcalde pedáneo pasa a llamarse Presidente de la Junta Vecinal, denominación que conservará hasta la Ley de Bases de 1945.

\section{DE 1870 A 1924}

La Ley municipal de 2 de octubre de 1877 sigue la misma trayectoria que la de 1870, tratando de los Alcaldes de barrio en el artículo 36 , y dedicando el capítulo II del Título $30^{\circ}$ a la «administración de los pueblos agregados a un término municipal», reproduciendo en su artículo 90 el 85 de la Ley de 1870, y ocupándose de la Junta Vecinal y de su Presidente en los artículos 91 al 96. Un año antes, y en el Proyecto de ley sobre publicación de las leyes provincial y municipal reformadas por la de 16 de diciembre de 1876, se establece la división en distritos y barrios, con un Alcalde en cada barrio designado por el del Ayuntamiento y a las órdenes del Teniente de Alcalde del distrito, y para los pueblos agregados sigue la Junta Vecinal con su Presidente.

Todos sabemos que la Ley municipal de 2 de octubre de 1877 batió todos los records de vigencia en nuestro país en el sector local, hasta que fue sustituida por el Estatuto municipal de 1924, pero en el interregno se produjeron, e incluso llegaron a ser aprobados en algún caso por la Cámara legislativa, aunque sin entrar en vigor, gran número de proyectos de leyes de Régimen local. Los más significativos trataban a los Alcaldes pedáneos y de barrio de la siguiente forma: el Proyecto de ley municipal de Venancio GoNzÁLEZ, de 12 de julio de 1886, habla de distritos, barrios y Alcaldes de barrio nombrados por el Ayuntamiento, y de la administración de los pueblos agregados con su Junta Vecinal, Presidente y dos o cuatro vocales. Los Alcaldes de barrio permanecen en el Proyecto de ley de 26 de mayo de 1894, que intenta refundir en una sola las leyes provincial y municipal. En el Proyecto de Bases de 11 de julio de 1903 - Proyecto MAURA- se vuelve a llamar Alcalde pedáneo al Presidente de la Junta Vecinal de los pueblos agregados, al igual que en las Bases fraguadas en 28 de enero de 1904. Y es curioso constatar que si bien el Pedáneo no figura en las Bases iniciales del Proyecto de Romanones de 3 de febrero de 1906, su inclusión 
fue interesada por los Diputados BARRo y MIER en su enmienda titulada «Pueblos agregados a un Municipio». La Junta Vecinal con su Presidente, y no pedáneo, figura en el Proyecto La Cierva de 31 de mayo de 1907, al igual que la posibilidad por parte de los Alcaldes de nombrar Alcaldes de barrio u otros auxiliares de su gestión.

\section{DE 1924 A 1975}

Y ya entramos en lo inmediato, en la legislación que por más próxima hemos manejado más asiduamente. El Estatuto municipal de 8 de marzo de 1924 mantiene la figura del Alcalde.de barrio en su artículo 100, pero en la revisión legislativa efectuada por el Decreto de 16 de junio de 1931 se le suprime, y la Ley municipal de 31 de octubre de 1935 no menciona a los Alcaldes de barrio en su articulado. Es más, el artículo 83 de la misma, al establecer que el Alcalde podrá delegar parcialmente sus atribuciones en los Tenientes de Alcalde y Concejales y que esta delegación en los Municipios de población diseminada podrá ser total para cada poblado si se hace a favor de un Concejal vecino del mismo, impide de hecho la existencia de los Alcaldes de barrio.

Estos reaparecen en la Base sexta de las de Régimen local de 1945 y en la vigente Ley de Régimen local, texto refundido de 24 de junio de 1955, artículos 70 y 71 , en los que se dice que el Alcalde, en los poblados y barriadas separados del casco urbano y que no constituyan Entidad local menor, podrá nombrar un Alcalde de barrio para cada núcleo entre los vecinos que residen en éste, y que también podrá nombrar como auxiliares, y con las facultades que expresamente les delegue, Alcaldes de barrio en las ciudades en que los servicios requieran esta designación.

En la Ley 41/1975, de 19 de noviembre, de Bases del Estatuto de Régimen local, no se habla de los Alcaldes de barrio, pero en una versión del texto articulado de dicha Ley que hemos manejado - aún no publicado ni vigente- se hace una regulación casi idéntica a la actual, ya que en el artículo 57 se dice: «En poblaciones y barriadas que no constituyan Entidad local menor, el Alcalde podrá nombrar un Alcalde de barrio para cada núcleo entre los vecinos que residan en éste»; y en el artículo 58: "También podrá nombrar el Alcalde, como auxiliares y con las facultades que expresa- 
mente les delegue, Alcaldes de barrio en las ciudades en que los servicios requieran esta designación».

Por lo que se refiere a los Alcaldes pedáneos, el Estatuto municipal de 8 de marzo de 1924 mantiene la denominación de la Ley de 1877 como Presidente de la Junta Vecinal, y en su artículo 106 establece que la designación de los miembros de la Junta se hará por elección, correspondiendo la presidencia al que reúna mayor número de votos, y caso de empate, al de mayor edad. También la Ley municipal de 31 de octubre de 1935 llama Presidente de la Junta Administrativa al de las Entidades locales menores, que se designa por elección entre los vecinos de la Entidad.

El nombre de Alcalde pedáneo reaparece en el artículo 69 de la vigente Ley de Régimen local, texto refundido de 24 de junio de 1955, que dispone: «En las Entidades locales menores habrá un Alcalde pedáneo que presidirá la Junta Vecinal y será nombrado por tiempo indefinido por el Gobernador Civil de la Provincia, a propuesta del Alcalde del Municipio respectivo, entre vecinos cabezas de familia con residencia en la Entidad", regulando ampliamente las «atribuciones del Alcalde pedáneo y de la Junta Vecinal» en la sección $4 .^{\text {a }}$ del capítulo III, artículo 124 , de la Ley y en diversos artículos del Reglamento de Organización, Funcionamiento y Régimen jurídico de las Corporaciones locales de 17 de mayo de 1952.

En las Bases del Estatuto de Régimen local de 19 de noviembre de 1975 no existen referencias expresas a los Alcaldes pedáneos, pero sí, en cambio, en ese texto articulado al que antes me he referido, y que nos dice que en las Entidades locales menores habrá una Junta Vecinal o Asamblea Vecinal con un Presidente o Alcalde pedáneo, y que dicho Presidente representará al Ayuntamiento y al Alcalde en el territorio de la Entidad, y a ésta en el Ayuntamiento, a cuyas sesiones deberá asistir con voto cuando se traten y resuelvan asuntos de interés directo para la misma, teniendo funciones análogas a las del Alcalde, circunscritas al territorio y competencia de la Entidad local menor; convocando y presidiendo las sesiones de la Junta o de la Asamblea Vecinal; decidiendo las votaciones en la primera con su voto de calidad; ejecutando sus acuerdos; ordenando sus pagos y rindiendo sus cuentas. De prosperar este texto de Ley articulada, y en relación con la situación actual, la figura del Alcalde pedáneo quedará indudablemente reforzada. 


\section{CONCLUSIONES}

Hemos trazado en una apretada síntesis la evolución histórica de unos cargos municipales de características singulares, y que dentro de un ámbito territorial reducido detentan o detentaron pequeñas parcelas del poder, propias o delegadas. Y hemos visto cómo los Alcaldes pedáneos nacen realmente al tiempo que se establece la organización municipal y persisten en ella a través de los siglos con funciones propias, aunque ejercidas en un territorio mínimo. Y lo mismo sucede con sus homólogos los mayordomos-jueces o mayordomos-pedáneos, de honda raigambre y tradición en algunas regiones de la Península, y cuyas funciones y competencias fueron similares o equivalentes a las de los Alcaldes pedáneos $\mathrm{u}$ ordinarios de las aldeas, desapareciendo su denominación, pero no sus funciones, que siguieron ejerciendo con el nombre que también detentaban de "pedáneos» a partir del establecimiento de los Ayuntamientos llamados constitucionales.

Los Alcaldes de barrio nacen más tarde, por razones administrativas y en principio con carácter ciudadano, mientras los Pedáneos han tenido siempre carácter rural. Unos y otros han desempeñado inicialmente funciones de carácter judicial, especialmente los Alcaldes pedáneos, que las han mantenido durante siglos, juntamente con otras de carácter político y administrativo. En la actualidad son las funciones y competencias administrativas las que caracterizan y definen tanto a los Alcaldes pedáneos como a los de barrio, con la diferencia de que los primeros, aunque reducidos, conservan funciones propias, mientras los segundos sólo las tienen delegadas.

La legislación, la no diferenciación, los ámbitos de actuación, han hecho que en la práctica se hayan confundido muchas veces las dos denominaciones, y que el término "pedáneo" se haya aplicado también a los Alcaldes de barrio.

En la actualidad, y de hecho siempre, aunque la falta de regulación en algunos períodos de los Alcaldes de barrio o de los Alcaldes pedáneos haya creado confusiones, se diferencian perfectamente los Alcaldes pedáneos de los de barrio: ni su nombramiento, ni sus funciones, ni su poder, son iguales. Las funciones del Pedáneo son, como ya dijimos, propias, tienen una competencia determinada, pequeña si se quiere, pero suya, mientras que el Alcalde de barrio no tiene más competencia ni funciones que las que graciosamente 
le delegue el Alcalde-Presidente de su Ayuntamiento. Y si alguien hoy «manda menos que un pedáneo» éste es precisamente el Alcalde de barrio.

En cuanto al futuro de estos cargos u oficios tan enraizados en la vida y en la legislación local debe ser, y así se vislumbra a través de las últimas regulaciones legales proyectadas, de continuidad e incluso de ampliación de funciones y de campos operativos. Las agrupaciones y fusiones de Municipios proyectadas tendrán en los Alcaldes pedáneos una forma posible de gobierno propio para las comunidades vecinales que se integren administrativamente, si queremos que las mismas pervivan como grupos sociales. Los Alcaldes de barrio pueden prestar un gran servicio en los Municipios urbanos y facilitar la descentralización y el acercamiento y relación con el vecino, especialmente en las grandes urbes, cuya identidad vecinal parecen buscar sus habitantes a través de agrupaciones más dimensionadas, más lógicas y humanas: calles, distritos, barrios. 